\title{
Is Idiopathic Benign Paroxysmal Positional Vertigo Associated with Serum 25-Hydroxy Vitamin D Deficiency?
}

\author{
(D) Belgin Tutar, (D) Güler Berkiten, (1) Fatih Akgün, (D) Semih Karaketir, (D) Onur Üstün, (DD Yavuz Uyar, (D) Ömür Biltekin Tuna \\ İstanbul Okmeydanı Training and Research Hospital, Clinic of Ear Nose Throat, Istanbul, Turkey
}

\section{Abstract}

Objective: Benign paroxysmal positional vertigo (BPPV) is a common cause of peripheral vertigo in the general population. We investigated the role of 25-hydroxy (25$\mathrm{OH}$ ) vitamin D deficiency in BPPV by comparing 25-OH vitamin D levels in healthy controls and in patients with BPPV.

Methods: 25- $\mathrm{OH}$ vitamin D levels of 125 patients with idiopathic BPPV who were diagnosed at our clinic between January 2018 and September 2018 and 101 healthy controls without vertigo were compared statistically.

Results: In this study, vitamin D deficiency was detected in patients diagnosed with BPPV, but there was no statistically significant difference with the control group. Conclusion: The prevalence of the vitamin D deficiency is very high in our population. Despite the major studies in the literature, vitamin D deficiency was not related to BPPV as a result of this research.

Keywords: Benign paroxysmal positional vertigo, 25-hydroxy vitamin D, peripheral vertigo

\section{INTRODUCTION}

Benign paroxysmal positional vertigo (BPPV) is the most common cause of peripheral vertigo in the general population (1). BPPV is characterized by vertigo that is triggered by head movements and lasts for seconds, and accompanied by a feeling of imbalance and nausea. In the pathophysiology of BPPV, there are two theories called cupulolithiasis and canalithiasis. There are three semicircular canals located perpendicular to each other in the inner ear and sensing the angular movements of the head: posterior, lateral (horizontal), superior (anterior) canal crura are associated with the utricle, known as autolytic organ. Calcium (Ca) carbonate crystals are found in the otoconial layer above the maculae found in the utricle. The otoconia separated from the utricle macula can pass into semicircular canals. Vertigo and nystagmus can occur when these otoconia stimulates cupula. The "canalithiasis" theory suggests that the free movement of these otoconia in the canal plays a role in the pathophysiology of the disease. It was first described by Hall, Ruby and McClure in 1979 and was first proven in vivo by Parnes and McClure in 1992. "Cupulolithiasis", defined by Schuknecht in 1969, refers to the adherence of the otoconia to the cupula (2). Otoconia contains Ca carbonate in the form of Ca crystals and an organic core consisting mainly of glycoproteins. Ca metabolism also plays a primary role in the synthesis/absorption of otoconia and is therefore theoretically thought to be an etiological factor at the onset of BPPV (3). The aim of our study was to compare 25-hydroxy (25-OH) vitamin D levels in patients with idiopathic BPPV and healthy controls, and to investigate the role of $25-\mathrm{OH}$ vitamin D in the development of BPPV.

\section{METHODS}

One hundred and twenty-five (100 female and 25 male, mean age $=52 \pm 14$ years) patients, who were admitted to the vertigo outpatient clinic between June 2018 and September 2018 and were diagnosed with idiopathic BPPV, were included in this retrospective case-control study. The patients had no history of Meniere's disease, vestibular migraine, labyrinth hypofunction, head trauma or other vestibular diseases. The control group 
consisted of 101 ( 74 female and 27 male, mean age $=48 \pm 13$ years) healthy volunteers. The patients had no history of neurological symptoms or vestibular disease. Patients with neurotologic symptoms and complaints of dizziness and imbalance were excluded from the study. All participants did not receive Ca or vitamin $\mathrm{D}$ treatment within the last year.

Vestibular evaluation was performed using computerized (videonystagmography: ICS Charter EP, GN Otometrics, USA). BPPV was diagnosed by Dix-Hallpike and Pagnini-McClure maneuvers. There was posterior canal involvement in 80 patients (64\%), horizontal canal involvement in 38 patients (30.4\%) and anterior canal involvement in seven patients (5.6\%). Epley maneuver was used in patients with posterior canal involvement and Barbecue maneuver was applied to those with horizontal canal involvement. In the anterior canal involvement, "reverse Epley maneuver" was performed. Canalithiasis was detected in 72\% (90 patients) of these patients and cupulolithiasis was responsible for the pathophysiology in 28\% (35 patients) (Table 1). Blood was collected from patients with BBPV and healthy volunteers and $25-\mathrm{OH}$ vitamin D levels were measured. $25-\mathrm{OH}$ vitamin $\mathrm{D}$ levels were classified as normal $(\geq 30 \mathrm{ng} / \mathrm{mL})$, insufficient $(>20$ to $<30 \mathrm{ng} / \mathrm{mL}$ ) and deficiency ( $\leq 20 \mathrm{ng} / \mathrm{mL}$ ). The approval of the Ethics Committee was obtained (dated: 6.11.2018, numbered: 48670771-514.10). Informed consent was obtained from the patients.

\section{Statistical Analysis}

Statistical analysis was performed using SPSS version 23.0. Descriptive data are presented using mean and standard deviation for normally distributed variables, and median, minimum and maximum values for non-normally distributed variables (and frequency tables for ordinal variables). Chi-square was used to compare categorical variables. The suitability of the measured variables to normal distribution was examined by visual (histogram) and analytical methods (Kolmogorov-Smirnov/ Shapiro-Wilk tests). Pairwise comparisons were performed using Student's t-test for normally distributed parameters and MannWhitney $U$ and Kruskal-Wallis tests for non-normally distributed parameters. $\mathrm{P}<0.05$ was evaluated as statistically significant.

\section{Results}

The mean serum $25-\mathrm{OH}$ vitamin D levels were $16.36 \mathrm{ng} / \mathrm{mL}$ (3.5253.91) in the BPPV group and $17.09 \mathrm{ng} / \mathrm{mL}(4.46-53.51)$ in the control group. Vitamin D levels were low in both groups. In the BPPV group, 81 patients (65.3\%) had serum 25-OH vitamin D deficiency, 33 patients (26.6\%) had insufficient and 10 patients (8.1\%) had normal levels. In the control group, 74 patients (73.3\%) had serum $25-\mathrm{OH}$ vitamin D deficiency, 16 patients (15.8\%) had insufficient and 11 patients (10.9\%) had normal levels (Table 2). There was no statistically significant difference between the BBPV

\begin{tabular}{|c|c|c|c|c|c|c|}
\hline & & $\mathbf{n}$ & $\%$ Median (minimum-maximum) & Vitamin D levels & $\mathbf{H}$ & $p^{a}$ \\
\hline \multirow[t]{2}{*}{ Affected canal } & Superior & 7 & 5.6 & $14.52(9.60-36.04)$ & \multirow{2}{*}{0.645} & \multirow{2}{*}{0.724} \\
\hline & Lateral & 80 & 64 & $16.18(6.12-49.78)$ & & \\
\hline
\end{tabular}

\begin{tabular}{|c|c|c|c|c|c|c|c|}
\hline \multirow{2}{*}{\multicolumn{2}{|c|}{$\mathbf{n}$}} & \multicolumn{2}{|c|}{$\operatorname{BPPV}(n=125)$} & \multicolumn{2}{|c|}{$\begin{array}{l}\text { Control group } \\
(n=101)\end{array}$} & \multirow{2}{*}{\multicolumn{2}{|c|}{ Significance }} \\
\hline & & $\%$ & $\mathbf{n}$ & $\%$ & & & \\
\hline \multirow[t]{2}{*}{ Gender } & Male & 25 & 20.0 & 27 & 26.7 & \multirow[t]{2}{*}{$x^{2}=1.429$} & \multirow[t]{2}{*}{$p=0.232$} \\
\hline & Female & 100 & 80.0 & 74 & 73.3 & & \\
\hline \multicolumn{2}{|l|}{ Age* $^{*}$} & \multicolumn{2}{|c|}{$52 \pm 14$} & \multicolumn{2}{|c|}{$48 \pm 13$} & $t=1.903$ & $p=0.058$ \\
\hline \multirow[t]{3}{*}{ Vitamin D groups } & Deficient $(\leq 20$ ng/mL) & 81 & 65.3 & 74 & 73.3 & \multirow{3}{*}{$x^{2}=3.952$} & \multirow{3}{*}{$p=0.139$} \\
\hline & Insufficient ( $>20$ to $<30 \mathrm{ng} / \mathrm{mL}$ ) & 33 & 26.6 & 16 & 15.8 & & \\
\hline & Normal ( $\geq 30 \mathrm{ng} / \mathrm{mL})$ & 10 & 8.1 & 11 & 10.9 & & \\
\hline \multirow[t]{2}{*}{ Vitamin D groups } & Deficient (<30 ng/mL) & 114 & 91.9 & 90 & 89.1 & \multirow[t]{3}{*}{$x^{2}=0.526$} & \multirow[t]{3}{*}{$p=0.468$} \\
\hline & Normal ( $\geq 30 \mathrm{ng} / \mathrm{mL})$ & 10 & 8.1 & 11 & 10.9 & & \\
\hline \multicolumn{2}{|l|}{ Vitamin D value** } & \multicolumn{2}{|c|}{$16.36(3.52-53.91)$} & \multicolumn{2}{|c|}{$17.09(4.46-53.51)$} & & \\
\hline
\end{tabular}


group and control group in terms of $25-\mathrm{OH}$ vitamin D deficiency $(p=0.139)$. There was no difference between $25-\mathrm{OH}$ vitamin $\mathrm{D}$ levels in BPPV patients regarding affected canals $(p=0.724)$.

\section{DISCUSSION}

BPPV is the most common cause of peripheral vertigo at any age. The mechanism of BPPV is explained by the passage of the otoconia separated from the utricle into semicircular canals. There is no consensus on the factors that cause BPPV. Since the etiologic factors are unclear, most cases are considered idiopathic. Predisposing factors are senility, female gender, hormonal factors and viral causes (4). Inner ear consists of cochlea and labyrinth system. The bony labyrinth consists of three semicircular canals: superior (anterior), posterior and horizontal (lateral). There is a fluid called perilymph in the bony labyrinth. Membranous labyrinth consists of utricle, saccule and membranous semicircular canals, and it contains endolymph. Membranous semicircular canals are located perpendicular to each other. The dilated parts are called ampulla. There are special cells in this region called "crista ampullaris" that is the sensory organ of balance. Within the wall of the utricle, there are cells called the macula of utricle, which lie horizontally and receive the sense of balance, and supporting cells. These cells have $\mathrm{Ca}^{+2}$ particles called otoconia. Otoconia crystals have central and peripheral portions. The core is predominantly organic with a lower $\mathrm{Ca}^{+2}$ level and the periphery is largely inorganic with a higher $\mathrm{Ca}^{+2}$ level (5). Endolymphatic $\mathrm{Ca}^{+2}$ concentration is critical for normal auditory and balance system (6-8). According to theoretical considerations, a link between otolytic disorders and vitamin D deficiency is highly probable. Endolymphatic (cochlea $23 \mu \mathrm{M}$ and vestibule $280 \mu \mathrm{M}$ ) Ca concentration is much lower than perilymph. Yamauchi et al. (9) first demonstrated the expression of a complete $\mathrm{Ca}^{+2}$ absorptive system in cochlear and vestibular tissues in mice. Regulation by vitamin $\mathrm{D}$ allows this system to be regulated at the transcript level. Brookes (8) thinks that low endolymphatic $\mathrm{Ca}^{+2}$ concentrations at pathological level are the cause of hearing loss due to vitamin D deficiency and hypoparathyroidism. Karataş et al. (3) conducted a study in our country and compared the prevalence of osteoporosis and vitamin D deficiency in 78 BPPV patients and in 78 controls. Osteoporosis and vitamin D deficiency rates in BPPV patients were very high. The mean serum $25-\mathrm{OH}$ vitamin D levels in BPPV patients and controls were $23.0 \pm 14.4 \mathrm{ng} / \mathrm{mL}$ and $17.0 \pm 12.3 \mathrm{ng} /$ $\mathrm{mL}$, respectively. The prevalence of vitamin D deficiency in these two groups was 28\% (22 individuals) and 40\% (31 individuals), respectively. However, there was no significant difference in the prevalence of osteoporosis and vitamin D deficiency between
BPPV group and controls. Since the prevalence of osteoporosis and vitamin D deficiency is quite high in the general population, they thought that osteoporosis and vitamin D deficiency are not risk factors for BPPV. In our study, mean serum 25-OH vitamin D levels were $16.36 \mathrm{ng} / \mathrm{mL}$ (3.52-53.91) in the BPPV group and $17.09 \mathrm{ng} / \mathrm{mL}$ (4.46-53.51) in the control group. Vitamin D levels were low in both groups. There was no statistical difference between the groups. Lee et al. (4) evaluated the relationship between $\mathrm{Ca}^{+2}$ and vitamin D status, and the presence of BPPV formation and bone biochemical markers in 132 osteoporotic patients diagnosed with idiopathic BPPV. They divided patients into three groups according to bone mineral density (BMD). The incidence of vitamin D deficiency was $11.8 \%(4 / 34)$ in the normal BMD group, $15 \%(6 / 40)$ in the osteopenia group, and $43.1 \%(25 / 58)$ in the osteoporosis group. They found a positive correlation between $25-\mathrm{OH}$ vitamin $\mathrm{D}$ and BMD results in BPPV patients. They reported that the prevalence of BPPV in osteoporotic patients is associated with vitamin D deficiency and systemically high bone turnover rates, and may impair local $\mathrm{Ca}^{+2}$ homeostasis in the inner ear. Han et al. (10) examined the BMD and serum $25-\mathrm{OH}$ vitamin D levels of 80 postmenopausal women with BPPV and compared them with healthy volunteers. Decreased BMD was significantly higher in women with BPPV than in healthy controls (71.8\% vs. $51.2 \%)$. Mean serum $25-\mathrm{OH}$ vitamin D levels were also significantly lower in women with BPPV than in healthy controls (19.1 \pm 5.2 vs. $22.5 \pm 5.8, p<0.001)$. They thought that low $25-0 H$ vitamin D might be a risk factor for BPPV in the postmenopausal period. Maslovara et al. (11) compared serum vitamin D vitamin levels in BPPV patients with and without recurrence, and found no significant difference. Most of the patients found low serum vitamin D level and recommended vitamin D for these patients. Vitamin D levels were significantly lower in patients with clinical canalithiasis than cupulolithiasis. In our study, $72 \%$ of cases had canalithiasis pathology and $28 \%$ had cupulolithiasis. There was no difference in vitamin $D$ deficiency.

Talaat et al. (12) divided 80 patients (52 females, 28 males, mean age $=47.6 \pm 9.1$ years, range $=31-71$ years) with BPPV into two groups: 36 patients with primary and 44 patients with recurrent BPPV. The control group included 100 healthy volunteers with similar age and gender distribution. BMD and serum $25-\mathrm{OH}$ vitamin D were measured. Vitamin D levels were significantly lower in the recurrence group $(p<0.05)$. Studies that correlate BPPV and both vitamin D deficiency and low BMD suggest that these disorders should be investigated and treated in patients with recurrence. Büki et al. (13) measured 25-OH vitamin D levels in 18 BPPV patients and found it to be low. Four of these patients were recurrent cases with 4-6 attacks per year. Patients with idiopathic 
positional vertigo had a low mean serum $25-\mathrm{OH}$ vitamin $\mathrm{D}(23$ $\mathrm{ng} / \mathrm{mL}$ ) levels similar to that of the general Austrian population at high rates. Patients with recurrences were given vitamin $D$ and their serum levels were corrected. They were followed-up for 8 months and vertigo attacks did not recur after vitamin D supplementation. They suggest further epidemiological research to determine whether BPPV patients with low vitamin D levels may benefit from supplementation and the effect of correcting vitamin D deficiency on vertigo recurrence. Jeong et al. (14) measured $25-\mathrm{OH}$ vitamin D serum levels in 100 patients (63 female and 37 male, mean age $=61.8 \pm 11.6$ years) with idiopathic BPPV and compared the data with 192 controls (101 female and 91 male, mean age $=60.3 \pm 11.3$ years). Serum $25-\mathrm{OH}$ vitamin D level was lower in BPPV patients (14.4 \pm 8.4 vs. $19.1 \pm 6.8 \mathrm{ng} /$ $\mathrm{mL}, \mathrm{p}=0.001)$. Moreover, patients with BPPV showed a higher prevalence of lower serum $25-\mathrm{OH}$ vitamin $\mathrm{D}(\leq 20 \mathrm{ng} / \mathrm{mL}, 80.0$ vs. $60.1 \%, p<0.001)$ than controls. It was shown that there was a relationship between idiopathic BPPV and decreased serum 25-OH vitamin D. Decreased serum 25-OH vitamin D may be a risk factor for BPPV.

\section{CONCLUSION}

The relationship between idiopathic BPPV and vitamin D deficiency is controversial in the literature. As in our country, vitamin $D$ deficiency is common in populations with short and variable sun exposure. We found low levels of vitamin $D$ in both study and control groups. In this respect, further studies are needed to investigate the relationship between BPPV and vitamin D deficiency.

\section{Ethics}

Ethics Committee Approval: Ethics committee approval was received for this study from the local Ethics Committee of Okmeydanı Training and Research Hospital (dated: 6.11.2018, numbered: 48670771-514.10).

Informed Consent: Informed consent was obtained from the patients.

Peer-review: Externally peer-reviewed.

\section{Authorship Contributions}

Concept: B.T., Y.U., Design: B.T., Y.U., Data Collection or Processing: G.B., Ö.B.T., Analysis or Interpretation: S.K., F.A., O.Ü., Writing: B.T.
Conflict of Interest: The authors declare no conflict of interest.

Financial Disclosure: The authors declared that this study has received no financial support.

\section{REFERENCES}

1. von Breven M, Radtke A, Lezius F, Feldmann M, Ziese T, Lempert T, et al.Epidemiology of bening paroxysmal positional vertigo: a populationbased study. J Neurol Neurosurg Psychitry 2007;78:710-5.

2. Parnes LS, Agrawal SK, Atlas J. Diagnosis and management of benign paroxysmal positional vertigo (BPPV). CMAJ 2003;169:681-93.

3. Karataș A, Acar Yüceant G, Yüce T, Hacı C, Cebi IT, Salviz M. Association of Benign Paroxysmal Positional Vertigo with Osteoporosis and Vitamin D Deficiency: A Case Controlled Study. J Int Adv Otol 2017;13:259-65.

4. Lee SB, Lee $\mathrm{CH}$, Kim YJ, Kim HM. Biochemical markers of bone turnover in benign paroxysmal positional vertigo. PLoS One 2017;12:e0176011.

5. Jang YS, Kang MK. Relationship between bone mineral density and clinical features in women with idiopathic benign paroxysmal positional vertigo. Otol Neurotol 2009;30:95-100

6. Tanaka Y, Asanuma A, Yanagisawa K. Potentials of outer hair cells and their membrane properties in cationic environments. Hear Res 1980;2:431-8.

7. Ohmori H. Mechano-electrical transduction currents in isolated vestibular hair cells of the chick. J Physiol 1985;359:189-217.

8. Brookes GB. Vitamin D deficiency--a new cause of cochlear deafness. J Laryngol Otol 1983;97:405-20.

9. Yamauchi D, Raveendran NN, Pondugula SR, Kampalli SB, Sanneman JD, Harbidge DG, et al. Vitamin D upregulates expression of ECaC1 mRNA in semicircular canal. Biochem Biophys Res Commun 2005;33:1353-7.

10. Han W, Fan Z, Zhou M, Guo X, Yan W, Lu X, et al. Low 25-hydroxyvitamin D levels in postmenopausal female patients with benign paroxysmal positional vertigo. Acta Otolaryngol 2018;138:443-6.

11. Maslovara S, Butkovic Soldo S, Sestak A, Milinkovic K, Rogic-Namacinski J, Soldo A. $25(\mathrm{OH})$ D3 levels, incidence and recurrence of different clinical forms of benig paroxysmal positional vertigo. Braz J Otorhinolaryngol. 2018;84:453-9

12. Talaat HS, Abuhadied G, Talaat AS, Abdelaal MS. Low bone mineral density and vitamin $D$ deficiency in patients with benign positional paroxysmal vertigo. Eur Arch Otorhinolaryngol 2015;272:2249-53.

13. Büki B, Ecker M, Jünger $H$, Lundberg YW. Vitamin D deficiency and benign paroxysmal positioning vertigo. Med Hypotheses 2013;80:201-4.

14. Jeong SH, Kim JS, Shin JW, Kim S, Lee H, Lee AY, et al. Decreased serum vitamin D in idiopathic benign paroxysmal positional vertigo. J Neurol 2013;260:832-8 